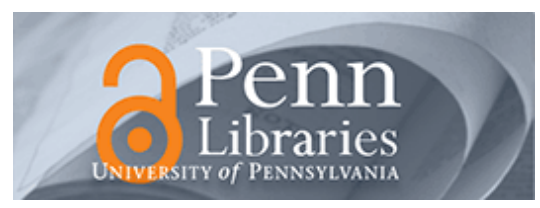

University of Pennsylvania ScholarlyCommons

1996

\title{
Voters, Candidates, and Campaigns in the New Information Age
}

Michael X. Delli Carpini

Follow this and additional works at: https://repository.upenn.edu/asc_papers

Part of the Communication Commons

\section{Recommended Citation}

Delli Carpini, M. X. (1996). Voters, Candidates, and Campaigns in the New Information Age. Harvard International Journal of Press/Politics, 1 (4), 36-56. https://doi.org/10.1177/1081180X96001004005

NOTE: At the time of publication, author Michael X. Delli Carpini was affiliated with Columbia University. Currently(May 23, 2013), he is a faculty member at the Annenberg School for Communication at the University of Pennsylvania.

This paper is posted at ScholarlyCommons. https://repository.upenn.edu/asc_papers/339

For more information, please contact repository@pobox.upenn.edu. 


\title{
Voters, Candidates, and Campaigns in the New Information Age
}

\author{
Abstract \\ New information technologies are slowly changing the conduct of campaigns and elections in the United \\ States. This article provides an overview and synthesis of extant research on the use of this technology \\ by candidates, journalists, and voters and discusses the implications for elections and democratic \\ governance in the United States. \\ Disciplines \\ Communication

\section{Comments} \\ NOTE: At the time of publication, author Michael X. Delli Carpini was affiliated with Columbia University. \\ Currently(May 23, 2013), he is a faculty member at the Annenberg School for Communication at the \\ University of Pennsylvania.
}




\title{
Voters, Candidates, and Campaigns in the New Information Age An Overview and Assessment
}

\author{
Michael X. Delli Carpini
}

New information technologies are slowly changing the conduct of campaigns and elections in the United States. This article provides an overview and synthesis of extant research on the use of this technology by candidates, journalists, and voters and discusses the implications for elections and democratic governance in the United States.

Campaigns and elections are the mainspring of politics in representative democracies, allowing for the periodic selection and reevaluation of public officials and providing moments of collective reflection and debate about public matters. For this process to work as intended, democracies require the means for elected officials and citizens to communicate effectively. Indeed, developments in communications technology-from the printing press to fiber optics-have gone hand-in-hand with developments in democratic politics.

Communications technologies are not neutral conduits, however. New forms of communication alter the way citizens and elites interact during campaigns. These technologies vary in important ways: the speed with which information is provided, the form the information takes, the range of information provided, the cost of producing and consuming the information, the scope of the audience, the extent of interaction between producer and consumer, and so forth. In addition, the views of citizens, interest groups, public officials, and the media regarding the uses to which technology should be put often differ, with short-term goals of profit, entertainment, reelection, and self-interest conflicting with broader notions of the public good. In short, changes in communications technology, even those that appear consistent with the consensus goal of an informed, engaged citizenry, raise important issues of content, access, and control.

Currently, political communications is undergoing changes driven largely but not exclusively by advances in technology. The role of this "new information technology" in campaigns and elections is embryonic, and thus far it has been used mainly in presidential campaigns and a limited number of senatorial, gubernatorial, and congressional races. In addition, its impact on campaigning, election coverage, and voter decision making remains uncertain. Nonetheless, if the past is any guide, there is little doubt that the nature of campaigns and elections at all levels will be profoundly affected over the next decade.

In this article, I provide an overview and synthesis of extant research on the uses of new information technology in campaigns and elections. The next section provides a brief description of the new technology and its relevance to the conduct of campaigns and elections. The following three sections explore the specific uses of this technology by the key actors in campaigns and elections: candidates, journalists, and voters. I conclude with a discussion of the implications of the new technology for elections and democratic governance in the United States.

\section{What Is the New Technology?}

Defining the new technology is no simple task. New forms of communication seldom replace older ones: The advent of print did not eliminate the spoken word, nor did the development of broadcasting eliminate print. Rather, new technologies interact with older ones to produce hybrid forms of communication. For example, print, the telegraph, and the photograph combined to restructure the form, content, and reach of newspapers (Emery and Emery 1988: 115-71). Radio had a similar impact on the spoken word (Delli Carpini 1993), and television combined visual and oral information into a new way of communicating (Meyrowitz 1985). In 
addition, changes in communications technology combine historic breakthroughs with more gradual developments, making the delineation of "new" and "old" somewhat arbitrary.

Nonetheless, recent advances have allowed for unprecedented recombinations of oral, written, and visual information. According to Jeffrey Abramson, Christopher Arterton, and Gary Orren, six related though sometimes contradictory properties distinguish new technologies from older ones (1988:4-5; 32-65). First, they dramatically increase the volume of information. Second, they make it possible to exchange information with little regard for "real" time and space. Third, they increase the consumer's control over what messages are received and when they are received. Fourth, they increase the sender's control over who receives what message. Fifth, they decentralize control over mass communications. Finally, they allow for greater and more timely two-way interactions.

Although numerous technologies share these properties (Abramson et al. 1988:5), several are central to changes in the conduct of campaigns and elections: cable, videocassette recorders, computers, satellites, cellular phones, faxes, "beepers"; and fiber optics. Though to date their use remains sporadic, they have-in conjunction with one another and with older forms of media - the potential to revolutionize the way candidates, journalists, and voters interact in campaigns and elections.

\section{Candidates and the New Technology}

The goal of a campaign, from the candidate's point of view, has not changed over the past two hundred years: to convince a plurality of voters that your specific platform, general vision, and personal qualities are preferable to those of your opponents. Achieving this goal has always required the use of mediating institutions; even in the earliest U.S. elections, candidates for all but the most local offices could interact personally with only a small percentage of the citizenry. In the nineteenth and early twentieth centuries, the central mediators were political parties and the print media. Political parties provided a degree of programmatic coherence as well as campaign workers and surrogate speakers to spread the word about the candidates (Burnham 1970).

Newspapers, which were affiliated with political parties or specific ideologies for most of the nineteenth century, also spoke to the positive qualities of their favored candidate and the programmatic and personal shortcomings of the opposition (Emery and Emery 1988:89-243).

With the rise of an independent press, advances in electronic communication, and the decline of political parties, candidates entered a campaign environment that was both more hospitable and more threatening to their electoral chances. Partially freed from the constraints of party organization, they could develop platforms and images that were tailored to their personal strengths and the interests of their specific constituencies. The telegraph, radio, and television allowed greater, quicker, and more direct access to the public. However, a more independent press meant less control over the content and tone of coverage. Candidates increasingly developed a dual strategy, one for the "paid media" (political ads) and one for the "free media" (newspaper, radio, and television coverage). The former required developing messages that would appeal to voters and getting those messages to as many voters as possible. The latter required packaging messages in ways that would pass through journalistic filters as unscathed as possible (Salmore and Salmore 1985: 115; 145-66).

Recent advances in technology have aided candidates in this dual strategy. By providing more effective ways to determine the public's wants, test the appeal of particular messages, identify and reach different segments of the electorate, and monitor the success of various strategies, candidates are better able to tailor their messages in ways that resonate with citizens. In addition, new technologies allow campaign organizations to provide information to journalists in ways that increase candidate control over how they are presented to the 
public. The new technology allows candidates to bypass journalistic filters, blurring the distinction between paid and free media.

\section{Campaign Research}

A major function of campaign organizations is collecting information about your opposition, your candidate, and the public. New technology has greatly enhanced this process. As early as 1984, the Republican National Committee devoted more than a million dollars to its Opposition Research Group (ORG). Members of ORG sifted through thousands of publications and documents, collecting information on potential opponents to Ronald Reagan. The information was entered on a mainframe computer and organized to allow easy access by nonexperts. By the time of his nomination, ORG had collected 75,000 items on Walter Mondale including 45,000 direct quotes (Abramson et al. 1988:92). This information, updated every twenty-four hours, was used throughout the campaign to attack the Democratic candidate or challenge his campaign statements.

Recent advances have eased this process of information gathering. On-line data bases like Nexis allow campaign organizations easy-though costly-access to any story written over the last decade in hundreds of local and national publications, eliminating the laborious task of searching through actual texts. The development of powerful laptop computers and high-speed modems has all but eliminated the need for mainframe computers and allows greater flexibility in when and where information is accessed and used. On-line services (for example, America Online, CompuServe, and Prodigy) provide access to government publications, presidential statements, federal court decisions, the major wire services, daily newspapers, academic and historical material, and the like, aiding in opposition research and the development of candidate image, policy statements, and position papers. An even larger array of data bases can be accessed directly through the Internet.

\section{Fund Raising and Targeting Potential Supporters}

The new technology also aids in fund raising and targeting supporters. For example, during the 1988 Democratic primaries, callers could dial a 900 phone number and hear a prerecorded message from Jesse Jackson, for which they were automatically billed \$20. During the 1992 primaries, Jerry Brown received an estimated five million dollars from 250,000 callers to his 800 number (Freedom Forum 1992a:28). Ross Perot also made extensive use of an 800 number in 1992. In addition to fund raising, these numbers allow candidates to provide information to voters.

Mailing lists, often compiled through computer and laser scanning technology, allow candidates to target potential supporters based on their reading preferences, consumption patterns, or place of residence. Indeed, one of the major benefits of 800 and 900 numbers, candidate e-mail addresses and home pages, call-in talk shows, and on-line forums is the identification of potential supporters. For example, the Perot Committee, using a caller-recognition system and a data-matching service, compiled a data base combining individual callers' phone numbers with demographic information about the communities in which they lived. This allowed the Perot campaign to identify not only actual supporters, but also the types of individuals and communities from which future support might be drawn (Arterton 1993:88-89).

Computers have also enhanced campaign organizations' ability to use aggregate data to identify areas of support and opposition. For example, during the 1993 New York City mayoral race, the Dinkins campaign used census, registration, and voting records to divide census tracts by levels of likely support. Limited campaign resources were then targeted to communities viewed as having the greatest potential for improvement.

\section{Finding the "Hot Buttons": Voter Response Analysis}


The new technology has enhanced candidates' ability to develop messages that strike a "responsive chord" with voters (Schwartz 1973). Although the use of image and sound has always been important in campaign advertising (Diamond and Bates 1993), advances in computer graphics and video techniques have greatly improved the quality (and potential effectiveness) of political spots. In addition, spots can be produced more quickly than in the past, allowing candidates to react rapidly to changes in the political environment. For example, in 1992 the Clinton campaign was able to script, produce, and air a campaign commercial responding to a Bush attack within twenty-four hours.

The effectiveness of political ads has also been enhanced by the increasingly sophisticated use of market research. The combination of opinion polls, focus groups, and audience response technology is a powerful tool in creating ads that raise issues of public concern in ways that are emotionally charged. For example, the Bush campaign strategy of attacking Michael Dukakis's veto of the mandatory pledge of allegiance bill, his opposition to mandatory sentencing for drug offenders, and the Massachusetts prison furlough program emerged from a 1988 focus group. The focus group revealed that although voters did not react very negatively to anyone of these issues, their combination led to serious doubts about Dukakis's leadership ability and political ideology (Kolbert 1992:20).

Although most focus groups are decidedly low-tech, they are increasingly combined with "continuous on-line audience response" (COAR) technology to gauge participants' emotional responses. COAR systems are the sophisticated stepchildren of the Lazarsfeld-Stanton Program Analyzer, developed in the mid- 1940s (Biocca and David 1992). Advances in computer technology and video graphics have made their use more common (and valuable) in candidate research. Typically, each participant has a small "dial box," on which there is a knob and several settings. The settings correspond to a scale (for example, from strongly dislike to strongly like), with the middle position being neutral. Participants move the dial as they view a video clip or campaign ad, and their second-by-second responses are summarized and plotted on a graph, which is instantly superimposed on a television image of the video or ad. (This graph is not visible to the participants themselves.) Consultants can then determine how the group as a whole or specific types of voters reacted to particular points in the video, using this information to refine the form and content of a candidate's message. This technology was used by both the Clinton and Bush campaigns to gauge voter reactions to Bush's 1992 State of the Union Address (Kolbert 1992:18-20).

Computer-assisted interview (CATI) systems have also aided in the conduct and analysis of poll data, allowing campaign organizations to track voter reactions to the events of a campaign and to adjust their strategy accordingly. For example, tracking polls were instrumental in the Clinton campaign's decision to delay the airing of their more positive "vision" ads late in the 1992 campaign and to respond directly to the negative ads being aired by the Bush campaign.

\section{Reaching the Voter}

At the heart of any campaign is contact with voters. The new technology has refined the ability to do this at both a mass and a more targeted level. As mentioned earlier, 800 and 900 numbers allow candidates to speak "directly" to self-selected voters. These messages often address specific issues and policies deemed of interest to a segment of the public while providing a sense of connection with the candidate as an individual. This connection need not always be positive. For example, during the 1992 presidential campaign, maverick Republican Floyd Brown (creator of the infamous Willie Horton ad) established a 900 number allowing callers to listen to excerpts of conversations between Bill Clinton and his alleged mistress, Gennifer Flowers.

Radio and television talk shows serve a similar purpose to 800 and 900 numbers, allowing voters to talk directly with candidates and their surrogates. Talk shows have the added benefit of being live conversations that 
can be heard not only by the caller, but also by often sizable viewing and listening audiences. In addition, television talk shows add visual cues to the interaction. As mentioned earlier, the use of caller-recognition systems and data-matching services can provide a wealth of information for developing both mass communications strategies and more targeted approaches to contacting voters.

In recent elections, the logic of telephone contact has been extended to the personal computer. During the 1992 Democratic primaries, Jerry Brown spent an hour at CompuServ headquarters, "chatting" with on-line users (Freedom Forum 1992a: 31). The Clinton campaign provided information regarding the candidate and his policies through a number of large (CompuServ, Prodigy) and lesser known electronic bulletin boards. Such practices appear to be growing. By late 1995, every major candidate for the Democratic and Republican presidential nominations had established a home page on the World Wide Web.

Computerized contact with voters serves two important functions for candidates. First, it provides detailed information to a small but potentially important and self-motivated group of voters. Second, it provides the campaign with useful, detailed information regarding public attitudes about the candidate and the issues of the day. In theory, other "on-line" behavior of users who contact a candidate (for example, what other bulletin boards and services they use, what screens they look at, what messages they send) can be matched to their political views, allowing campaigns to develop a sophisticated profile of supporters and detractors, as well as a strategy of how best to contact and appeal to them. To date, however, this information has been treated as proprietary by the computer services and has not been shared with candidate organizations.

Candidates have also made increasing use of videocassettes to contact voters. For example, during the 1992 New Hampshire primary, the Clinton campaign distributed thirty thousand videotapes to undecided voters (Arterton 1993 :92). The tapes, which were delivered door-to-door, featured ten minutes of Clinton talking about his life and views. Ross Perot also made extensive use of videotapes during his independent run for the presidency: more than 300,000 copies of three different tapes, ranging in price from $\$ 9.95$ to $\$ 19.98$, were made available to interested citizens (Freedom Forum 1992a:32).

Satellite feeds provide an additional channel for candidates to reach voters without passing through traditional journalistic filters. Private residences and public facilities equipped with satellite dishes can directly access live or prerecorded messages from the candidates, a technique used by all three candidates during the 1992 presidential campaign. The audience for direct access is limited-about twelve million households have satellite dishes (Times Mirror 1995). Nonetheless, the potential nationwide audience was large enough for USA Today to list the satellite coordinates for a Perot "town hall meeting" held in Orlando, Florida (Freedom Forum 1992a:32).

The technologies discussed here require citizens to seek out information provided by candidates. Although to date the number of citizens willing and able to do this is relatively small, they disproportionately consist of community leaders, campaign contributors, and likely voters, making them especially valuable. In addition, the increase in television channels brought about by cable and, in the near future, by fiber optics and changes in the use of the broadcast spectrum allows for a middle ground between the large but relatively undifferentiated audience provided by the traditional networks and the homogeneous but relatively small audiences provided by computer bulletin boards and the like. Messages can be tailored to specific audiences, such as those for MTV, the Christian Broadcasting Network, and the Black Entertainment Network, and even to the audiences for particular shows, allowing an unprecedented blending of personal and mass communication.

\section{Rapid Response}

The new technology not only enhances the ability of campaigns to communicate with voters, but also aids in communication within the campaign organization itself. Laptop computers, cellular phones, faxes, and 
beepers keep campaign strategists in touch with one another and their candidate, allowing for almost instantaneous adjustments in strategy as new events unfold. The Clinton campaign perfected this rapid response approach, monitoring wire services and twenty-four-hour news networks and shadowing the opposition. This information was used to adjust both broad strategies and specific tactics, thus refining the art of spin and damage control.

On several occasions, this technique was used to make changes in Clinton's public statements moments before they were delivered. Similarly, media consultants at Clinton headquarters would routinely monitor satellite feeds from the campaign's cameras, which were set up to allow television stations around the country to select clips for their evening news broadcasts. If they noticed that the picture was less than optimal (for example, if it showed a sparse crowd or if Bush or Perot supporters were visible), they would contact the on-site advance staff via cellular phone to adjust the picture as it was being shot (Arterton 1993:92).

Computer bulletin boards also have been utilized internally by campaigns. For example, on-line forums like Election Techniques and Consultant let political consultants exchange notes and ideas regarding their general profession and issues tied to particular campaigns (Rittner 1993: 345; Smith and Gibbs 1994:575).

\section{Journalists and the New Technology}

New technology offers the news media many of the same opportunities presented to campaign organizations. Faxes, cellular phones, beepers, computers, and modems are freeing journalists from many of the traditional constraints of time and space, creating what has been called a "virtual newsroom" (Freedom Forum 1992c:70). Journalists have access to data bases and on-line services, allowing them to augment traditional news sources and put stories in historical and social perspective. More generally, the new information environment is changing the way news organizations interact with citizens and campaign organizations.

\section{On-line Journalism}

According to a survey of 104 print and broadcast journalists, the media have definitely entered the computer age. While on the campaign trail in 1992, 90 percent used portable computers; 84 percent used modems for computer-to-computer communications; 83 percent used faxes; 60 percent connected to newsroom computers; 50 percent used electronic beepers; 47 percent used voice-mail to communicate with the newsroom; 46 percent used cellular phones; 40 percent accessed electronic libraries; and 25 percent connected with commercial data bases (Freedom Forum 1992c:72). This electronic network has facilitated news gathering in three ways: It allows access to a greater and more diverse range of sources, it allows greater flexibility in how information is presented, and it allows more up-to-date reporting.

The most evident impact of new technology is the ability to communicate quickly with the newsroom and to do so from a wider range of locations than was once possible. Using faxes or computer-to-computer transmissions (most commonly through Telnet, CompuServe, and the Associated Press Network), reporters can file stories, update facts, and edit copy much closer to their filing deadlines than ever before. Cellular phones and beepers allow reporters to remain in regular contact with the home office (and vice versa), giving them greater flexibility in following candidates, other campaign principals, and potential leads.

A common complaint of journalists is finding reliable hookups for electronic transmission, especially in out-of-the-way places. During the 1992 presidential campaign, reporters for the Boston Globe solved this problem by connecting to the home computer via cellular phone, thus eliminating the need to be directly wired. This innovation, likely to be used more extensively in the future, further frees reporters from time and space limitations. 
In addition, the use of modems lets journalists combine face-to-face sources with information from the wire services, the news organization's main computer, commercial data bases (such as Nexis, VuText, and Dow Jones), and more consumer-oriented services like Prodigy and CompuServe. For example, the privately owned Federal News Service provides "verbatim transcripts of all presidential statements, briefings by the White House, State Department and other departments, as well as statements, speeches and interviews of major policy makers" (Freedom Forum 1992c: 77). These data bases and wire services help shape story ideas, suggest leads, and provide factual information and quotes. The new technology can also be used to provide background information to correspondents in the home office. According to the Washington Post, "ABC, CBS, and NBC have staffed most of the [1992] primaries with young producers who gather endless tidbits for computerized memos fed to the star correspondents back in Washington." 1

Electronic sources are also available through facsimile technology. Newsletters like Hotline and Campaign Countdown provide daily or weekly transmissions that summarize and excerpt from the national print and broadcast media, giving journalists "useful nuggets, from the latest campaign ads and tracking polls to TV pundit predictions to Jay Leno's one-liners." ${ }^{2}$

About 10 percent of journalists also use spreadsheet software, such as Lotus, allowing for more statistically oriented research. At this level, journalists are as much social scientists as news reporters, approaching the kind of "scientific" or "precision" journalism advocated by John Dewey (1927) and Philip Meyer (1991).

\section{The Presentation of Information}

The new technology has also affected the way in which information is presented. Using computer graphics, the media can more effectively present statistical and visual information and is more likely to do so than ever before. Although some graphics (especially in television news) are more form than substance, much of it is informative and allows for the presentation of complex material in more readily accessible ways. This is especially true for the presentation of survey data, where pie charts, histograms, and trend lines allow for greater detail and useful context. Graphics also aid in the presentation of background information, such as maps and sidebars that provide historical, biographical, or contextual information not normally considered "news," but valuable for readers and viewers who may not have their own store of knowledge to draw on.

The ability to transmit photographs and video electronically (via satellite or fiber optics) has made visual material much more accessible to news organizations. Electronic transmission has also extended the audience of major news outlets. National newspapers like USA Today and the national editions of the New York Times and Washington Post are made possible by satellite technology, as are twenty-four-hour news services like CNN and C-SPAN, and "superstations" like TBS. Several daily newspapers are also available electronically through on-line services like Prodigy and CompuServ.

\section{Shaping the Media Environment: Candidate Organizations}

In theory, the new technology allows journalists greater independence in deciding what's news. However, campaign organizations and other political groups have used this technology to influence what is reported and how it is packaged. For example, some campaigns now provide "actualities," or prerecorded sound bites that are made available to radio stations through 800 numbers. News organizations can record excerpts from these messages and use them in their daily news broadcasts.

Video news releases (VNRs) provide a similar service for television. These are prepackaged videos produced by candidate organizations and sent directly to news stations in the form of videotape or satellite transmission. Although VNRs allow local stations to air different material from that presented by the networks, it also allows candidates greater control over the images and text that are broadcast, thus blurring the line 
between free and paid media. Though news organizations are reluctant to use VNRs, economic incentives and production advantages led about 12 percent of local stations to do so during the 1992 campaign, up from about 3 percent in 1988 (Freedom Forum 1992b:41).Although the majority of stations airing VNRs edit them, the fact that the initial video is controlled by the candidates raises troubling issues regarding the independence of news coverage.

More common than VNRs are satellite interviews with candidates or their surrogates (Freedom Forum 1992b:37). Forty-four percent of a random survey of news directors said their stations had conducted at least one such interview during the 1992 campaign (the average number of interviews was four), up from 20 percent in 1988. These remote interviews allow candidates to reach large audiences efficiently while tailoring messages to particular localities. In turn, media outlets can provide local spins on the campaign, distinguishing their coverage from that of the networks and national media. Because candidate organizations usually pay for the satellite links and news organizations save the expense of sending a crew to interview the candidate, remotes can be cost-effective. Although satellite interviews allow reporters more control over the news product than VNRs, candidates are often able to shape the coverage to their advantage, especially because local anchors and reporters are less schooled at interviewing national candidates than are national reporters.

Campaign organizations can also feed information directly to journalists via faxes. Presidential campaigns routinely send press releases simultaneously to hundreds of news organizations, journalists, and columnists, aided by computerized phone lists and automated dialing. Although this provides the media with easy access to the campaigns, it also gives greater "spin control" to campaign organizations, which can react to breaking issues with lightning speed (Stern 1992). Campaign organizations have even taken advantage of journalists' use of beepers, using them to contact individual reporters or assemble the campaign press corps quickly for important announcements-what one campaign operative termed "calling home the cows" (Freedom Forum 1992c:78).

\section{Shaping the Media Environment: The Public}

New technology has also given a greater, if sometimes distorted, voice to the public in campaign coverage. The increased use of polls in general and "instant polls" in particular has made the public an important player in spin control. Whereas computer-assisted interviews allow media organizations to conduct and disseminate scientifically accurate polls very quickly, polls and forums that require 800 or 900 number call-ins are less likely to be representative and thus are more troublesome. For example, a 1993 Times Mirror survey found that callers to talk-radio shows were disproportionately male, Republican, and conservative (1993:10). Similarly, the use of "people-on-the-street" interviews (and, increasingly, "families-in-the-home" interviews and on-the-air focus groups), although providing useful personal insights, can unintentionally misrepresent broader public opinion.

"Deliberative polls," in which random samples of citizens are brought together to discuss political issues, are an interesting if controversial blend of new technology, traditional mass media, and face-to-face conversation (Fishkin 1995). For example, in early 1996, five hundred citizens were assembled in Texas for several days of small-group discussions and interaction with candidates and policy experts. The logic of this' assembly was as old as democracy itself: providing citizens the opportunity to deliberate face-to-face in order to come to an informed public judgment. Yet this modern-day town meeting depended on both traditional mass media and new technology. Computers and the science of polling were crucial to the selection of participants and the rapid analysis and reporting of data. Satellite technology and cable allowed the broadcasting of the event (much of it live) to a national audience, and television (specifically, PBS) was the medium through which this national audience followed the deliberations.

COAR technology provides another way to measure public reaction to campaign events. On at least three occasions during the 1992 campaign, national news outlets (ABC, CNN, and MTV) broadcast graphics of 
citizens' moment-by-moment reactions to the presidential debates. For example, during the presidential debate in Richmond, Virginia, ABC's Nightline, a local ABC affiliate, and several local newspapers commissioned Virginia Commonwealth University to conduct a COAR study with one hundred undecided voters. Excerpts from the videotape formed the basis for Nightline's (and the local affiliate's) coverage of citizen reaction to the debate. The next day, the local newspapers published a running graphic of responses to the entire debate, annotated with excerpts from candidate statements. Reporters also used the COAR data to identify individuals who had changed their minds during the debate and interviewed several of these people for a follow-up story (Delli Carpini et al. 1993).

Election night coverage also has been affected by new technology. The use of exit polls and computers has moved the media beyond their traditional role of reporting simple vote counts. Throughout the evening, research analysts in New York City feed information to network anchors and nationwide affiliates. Requests for specific breakdowns of the vote or of public opinion allow different outlets to put their own spin on stories of local relevance, and computer graphics allow for the presentation of this data in more accessible, visually arresting ways.

Exit polls also give the media the ability to forecast election results before votes are counted. In the case of presidential races, these predictions have been aired before polls have closed in a number of states, raising concerns about their impact on turnout, voter attitudes, and the outcomes of lower-level races (Delli Carpini 1984). The print media also make use of exit polls, providing postelection analyses of how different segments of the public voted and why they voted as they did.

The technologies and methodologies discussed above give citizens greater voice in campaigns. They are not without risk, however. Poll results have the potential of becoming self-fulfilling prophecies, unduly influencing undecided voters. Nonrepresentative expressions of public opinion, if misinterpreted, can be misleading of the public mood. And instant polls and reactions can miss the more deliberative nature of public opinion, which often evolves over longer periods of time.

\section{Democratization or the New Pack Journalism?}

In theory, the new technology gives the media greater independence in covering campaigns. The use of "truth boxes," in which news media deconstruct campaign advertisements for their factual accuracy and production techniques, demonstrates how this technology can strengthen the media's hand in the battle for control over campaign messages. The competitive nature of elections allows journalists to play candidate organizations - and the information they provide - against one another. The use of public opinion polls and other means of citizen input provides an additional voice in the determination of newsworthiness.

Nonetheless, it is important not to overstate or romanticize changes in campaign coverage. Although new technology has eased deadline pressures, it has not eliminated them. The information explosion can overwhelm journalists and confuse priorities, and differences in technical skill and economic resources can limit, even bias, the use of new media.

Ironically, dependence on the same data bases and services has led some journalists to suggest that new technology has increased the centralization of information and the tendency toward pack journalism (Freedom Forum 1992c: 76). Cost considerations have led media organizations to pool their limited resources by sharing camera crews or conducting single exit polls on election nights. Under the pressures of information overload and still real deadlines, journalists often take the path of least resistance, which can mean depending on the well-packaged information provided by the candidate organizations themselves. Despite occasional public rebellions against negative campaigning, the media continue to emphasize horse race over substantive issues and drama over deliberation. As a result, much of the new technology is used to report on scandals, conflict, 
campaign strategy, and bottom-line poll results. Indeed, even when the media attempt to act responsibly-as when they deconstruct campaign advertisements - it is unclear whether such coverage inoculates citizens against misinformation and manipulative images or enhances the candidate organizations' ability to control the campaign agenda (Jamieson 1992:123-62).

\section{Voters and the New Technology}

New technology has begun to change voters' role in campaigns and elections, though it has done so differently depending on where on the socioeconomic ladder one is positioned. It is at this level that the new technology offers the most promise yet also raises the greatest concerns regarding issues of control and access.

\section{Access to the Information}

According to surveys conducted by the Times Mirror Center, there is great variation in the use of technology by citizens $(1994 ; 1995)$. Television and radio are almost universal in households. In addition, about 86 percent of households have a videocassette recorder. About 67 percent have cable, with households about evenly split between those with basic or premium services. More than a third of American households have computers, with half of these also having CD-ROM drives. One-in-five are equipped with computers and modems. About 8 percent have fax machines, and 6 percent are connected to satellite dishes.

Not surprisingly, there are significant economic biases in who is and is not "wired" to the new technology. For example, among households earning more than $\$ 50,000$ a year in 1994,75 percent had cable, 56 percent had a computer, and 27 percent had a modem. Among families earning between $\$ 20,000$ and $\$ 29,000$, however, only 58 percent had cable, 23 percent had a computer, and 7 percent had a modem. More dramatically, in 1995 73 percent of college graduates from households earning more than $\$ 50,000$ a year had a computer, compared with a mere 14 percent of those with a high school degree or less and from families earning less than $\$ 30,000$ a year. There are also significant differences between men and women and between whites and blacks, with whites and men more likely to own a computer or modem. Although these differences appear to be shrinking over time, the public remains dramatically divided in its access to information technology.

There are also regional disparities in access to the information superhighway. For example, a March 1994 New York Times article reported that whereas half of the population of Palo Alto, California, had home computers, modems, and access to the Internet, Significantly fewer than 10 percent of Chicago residents could make this claim. ${ }^{3}$

\section{The Information Elite: Using Computers and Modems}

Computers and modems provide potential access to the same information available to journalists and campaign organizations, though the cost of many professional on-line services is prohibitive. Commonly used services like Prodigy, CompuServ, and America Online provide a range of governmental, political, news-oriented, and educational data bases as well as numerous electronic bulletin boards for discussing political and social issues. They allow for communications with officeholders, government agencies, and candidates, and they provide access to the policy platforms, personal histories, and voting records of candidates for major office. By late 1995, there were more than fifteen hundred political and governmental home pages on the World Wide Web (Freedom Forum 1996).

To date, however, the Internet is more notable for its potential than its use. Only about half of the 20 percent of households with computers and modems actually use them to go on line. Among on-line users, about 72 percent have sent and received electronic mail, 69 percent have done research for work or school, 61 percent 
have accessed news data bases, 44 percent have participated in on-line forums and discussion groups (though only 15 percent have ever expressed an opinion about a political or social issue), 35 percent have received electronic news clippings from a friend or associate, and 10 percent have engaged in on-line political discussions or activities (Times Mirror 1995).

Research suggests that more informed citizens have different opinions than less informed citizens, are more politically active, and are more likely to vote consistent with their issue positions (Delli Carpini and Keeter 1996). Significantly, on-line users are more politically informed (and more likely to vote) than nonusers, though it is difficult to say whether this is because more knowledgeable citizens use the Internet or because on-line use increases political knowledge-most likely, both processes are at work (Times Mirror 1994, 1995). Either way, greater knowledge levels among on-line users suggest both the promise of this new technology and the dangers of its being used by a small and select segment of the public.

As with ownership, there are systematic differences in who uses computers and modems: Women, African-Americans, lower-income, and less-educated individuals use computers less frequently and are less likely to go on line than are men, whites, upper-income, and more-educated individuals. For example, only 4 percent of those with a high school degree or less from families earning less than $\$ 30,000$ a year have gone on line, compared with 35 percent of college graduates from families earning more than $\$ 50,000$. Although these demographic gaps are smaller among younger adults than older ones, they have not disappeared. For example, 28 percent of men under thirty go on line at least once a week, compared to 14 percent of women under thirty (Times Mirror 1995).

\section{The Partially Wired: 800 Numbers and Cable}

Cable and 800 numbers provide access to campaigns and elections to a broader segment of the population than do computers and modems. Most basic cable subscriptions include twenty-four-hour news services like CNN, nonpartisan political channels like C-Span, partisan or ideological talk shows like Rush Limbaugh, and specialty news provided by networks like the Christian Broadcasting Network and the Black Entertainment Network. Most also include local public programming with forums and news about local issues. As discussed earlier, call-in shows like Larry King Live, news call-in polls, and stand-alone 800 numbers also provide citizens with the means to gather information and have their opinions heard.

Nonpartisan and "good government" groups have also turned to 800 numbers to educate the public. During the 1992 campaign, Project Vote Smart provided a national "voter's research hotline" through which callers could get information about candidates for governor, Congress, and the presidency. This included biographical background; campaign finance history; key issue positions; addresses and phone numbers of campaign, district, and Washington offices; voting records for incumbents; performance evaluations by special-interest groups of varying ideological stripes; and information on how and where to register and vote (Center for National Independence in Politics 1993).

Although it is hard to determine how frequently such phone services and forums are used, there is some suggestive evidence. Despite difficulty in advertising its 800 number, ProjectVote Smart received more than 200,000 calls from March 16 through November 3, including 34,000 on election day alone. A 1993 Times Mirror study found that 61 percent of the public listens to talk radio at least occasionally, 11 percent have attempted to call in, and 6 percent have made it on the air. During the 1992 presidential campaign, when one of the networks experimented with a sophisticated 800 poll that allowed callers to use their touch-tone phones to answer a series of political opinion questions, the system was literally overwhelmed by millions of callers who attempted to participate. 


\section{Citizens as Political Consumers}

Despite the growing availability of interactive technology, politics remains a more passive activity for the vast majority of Americans, with most getting information from traditional sources like television and print. This does not mean that these citizens are unaffected by new technology, however. As noted earlier, candidate organizations, interest groups, and news organizations have used the new media to change the form and content of traditional information sources. Thus, those reading a newspaper or watching the news are receiving information that has been shaped by new technology. In addition, because candidates and the media use the new technology to monitor public sentiment, information provided through traditional venues at least partially reflects the preferences and views of politically passive citizens.

Nonetheless, differences in media consumption remain a reason for concern. Citizens who are most likely to use the new media are also most likely to use traditional news sources (Times Mirror 1994, 1995). These citizens are also better equipped to process and use information in their political calculus and more likely to discuss politics, give money, become involved in campaigns, and vote. Because evidence suggests that the political opinions and behaviors of uninformed citizens are less stable and consistent, their impact is diluted even when they do participate (Delli Carpini and Keeter 1996). As a result, both candidates and news organizations are more likely to respond to the views of the information elite. Citizens who are neither producers nor consumers of political information remain at the margins of the technological revolution and thus at the margins of the political process itself.

\section{Conclusion: The Costs and Benefits of the New Technology}

It is important not to overstate the current role of the new technology. To date, the greatest impact has been limited to national campaigns, the national media, and a small percentage of citizens, most of whom were already among the nation's information elite. Yet it would be equally naive to ignore changes that have occurred and, more importantly, are likely to occur over the next few years. Now, while the new technology is still in its formative stage, may be the best time to consider its potential costs and benefits.

The questions raised by the new technology are similar to those that have always been asked about the conduct of campaigns and elections: Is the amount and type of available information sufficient for citizens to make reasoned political judgments? Who controls the information that is available? Who has access to this information? Does the information serve to educate or manipulate the public?

\section{Volume and Content}

The amount of political information available today is greater than ever before, and much of it is of a quality that should enhance citizens' abilities to cast reasoned votes. Continued growth of the Internet and the likely tenfold expansion in television channels promise even more political and politically relevant information in the near future. However, the explosion in information has put an added burden on candidate organizations, journalists, and the public to sort through the chaff to find the wheat, leading some critics to suggest that we may be "informing ourselves to death" (Postman 1990). In addition, the increase in political information has brought an even greater increase in diversionary media: computer games, entertainment videos, home shopping networks, and the like. Indeed, it is likely that while the absolute amount of political information is increasing, the relative amount is shrinking. More strikingly, changes in the form and content of information is making the very distinction between news and entertainment obsolete.

\section{Control}


New technology promises a more democratic exchange of information, but the likelihood of this depends, in part, on who determines what information is available. Decisions as to what kinds of programming will be available on basic, premium, and pay-per-view cable; what data bases and electronic bulletin boards will be accessible through the major on-line services; which books, government documents, wire services, and newspapers will be available electronically; and so forth are critical if the new technology is to fulfill its democratic potential. Particularly important in this regard is the ideological and cultural balance of information that is made available (Bowie 1990; Firestone and Schement 1995).

Increases in the number of television channels, the expansion of data bases available through on-line services, the proliferation of discussion groups, the ease of setting up home pages, and so forth may make the issue of control less serious over time. However, the market-as opposed to civic-forces driving the new technology may work against the growth in accessible, relevant, and balanced political information.

\section{Access}

The new technology introduces substantial financial and informational costs. Because institutions and individuals vary in their ability to pay these costs, serious questions arise regarding the extent to which campaign information, and thus election outcomes, will be determined less by the issues and more by the relative abilities of interest groups, campaign organizations, and news outlets to use the new media. In addition, socioeconomic differences in the use of new technology, if not systematically addressed, raise the specter of a bifurcated electorate of information haves and have-nots.

Declines in the financial cost of new technology suggest that current disparities in elite and public access may be a temporary aberration. However, it is unclear whether computers, modems, and the like will ever become as universal as the television and telephone. In addition, the new technology, unlike media such as broadcast television, allow for a range of uses that vary in the skill and finances required to use them, making the simple presence of the requisite hardware in a campaign office, journalist's hands, or the home a relatively poor indicator of equal access. The pace at which new applications and technologies develop raises the real possibility that inequitable access to information may become a permanent condition of modern society.

\section{Education versus Manipulation}

The new technology provides a public space in which complex, shifting, often contradictory views can be discussed. It also provides access to facts and opinions that can be used to tether these discussions to the material world, giving the citizenry a common pool of information from which to draw. However, the new technology also reveals our wants, desires, beliefs, and prejudices in ways that make us subject to unprecedented manipulation. Campaign organizations, special interest groups, and media outlets can and do use this information to appeal to, reinforce, and even create these wants, desires, and prejudices.

Although the sheer number of information sources helps guard against this kind of manipulation, this increase, coupled with the refined ability of campaign organizations and the news media to target audiences with carefully crafted messages, raises the possibility of an informationally segregated citizenry in which different groups come to view the political world in starkly different terms. Although evidence suggests that fears about the fragmentation of the public are overstated (Neuman 1991; Times Mirror 1994, 1995), the future of the mass audience is by no means clear.

In the end, the new technology, in and of itself, will be neither a cure for the shortcomings of electoral politics in America nor the cause for the exacerbation of these shortcomings. A close examination of how the new technology has been used to date suggests that democracy requires not only the right to information and 
expression and the means to exercise that right, but also the will to use those means for civically appropriate ends.

\section{Notes}

1. Howard Kurtz, "Media Circus," Washington Post, July 12, 1992.

2. Howard Kurtz, "Hotline to Campaign Central," Washington Post, Feb. 29, 1992.

3. "Slipping through the Net," New York Times Magazine, Mar. 13, -1994, p. 18.

\section{References}

Abramson, Jeffrey B., F. Christopher Arterton, and Gary R. Orren. 1988. The Electronic Commonwealth: The Impact of New Technologies on Democratic Politics. New York: Basic Books.

Arterton, F. Christopher. 1993. "Campaign '92: Strategies and Tactics of the Candidates." In The Election of 1992, ed. Gerald M. Pomper. Chatham, NJ: Chatham House.

Biocca, Frank, and Prabu David. 1992. "Computerized Audience Response Measures for Mass Communication Research." Unpublished working paper, Center for Research in Journalism and Mass Communication, Chapel Hill, NC.

Bowie, Nolan. 1990. "Equity and Access to Information Technology." Annual Review of Institute for Information Studies, pp. $131-67$.

Burnham, Walter Dean. 1970. Critical Elections and the Mainsprings of American Politics. New York: WW. Norton.

Center for National Independence in Politics. 1993. Project Vote Smart: Inaugural Year Report. Corvalis, OR: Center for National Independence in Politics.

Delli Carpini, Michael X. 1984. "Scooping the Voters? The Consequences of the Networks' Early Call of the 1980 Presidential Race." Journal of Politics 46(3):866-85.

Delli Carpini, Michael X. 1993. "Radio's Political Past." Media Studies Journal 7(3):23-36. Delli Carpini 55

Delli Carpini, Michael X., and Scott Keeter. 1996. What Americans Know about Politics and Why It Matters. New Haven, CT:Yale University Press.

Delli Carpini, Michael X., Robert Holsworth, and Scott Keeter. 1993. "Consumer Journalism in the Electronic Age: Instant Reactions to the 'People's Presidential Debate.'" In The Finish Line: Covering the Campaign's Final Days. New York: Freedom Forum Media Studies Center; pp. 47-54.

Dewey, John. 1927. The Public and Its Problems. Chicago: Swallow Press.

Diamond, Edwin, and Stephen Bates. 1993. The Spot: The Rise of Political Advertising on Television. Cambridge, MA: MIT Press.

Emery, Michael, and Edwin Emery. 1988. The Press and America: An Interpretive History of the Mass Media. Englewood Cliffs, NJ: Prentice Hall.

Firestone, Charles M., and Jorge Reina Schement, eds. 1995. Toward an lnformation Bill of Rights and Responsibilities. Washington, D.C.: Aspen Institute.

Fishkin, James S. 1995. The Voice of the People: Public Opinion and Democracy. New Haven, CT: Yale University Press.

Freedom Forum. 1996. "Cybercampaigns Preach to the Choir." In The Media and Campaign '96, Briefing 1 (April): 8-10.

Freedom Forum Research Group. 1992a. "Calling All Voters: High Tech Connections in the Modern Presidential Campaign." In An Uncertain Season: Reporting in the Postprimary Period. New York: Freedom Forum Media Studies Center, pp. $28-33$.

Freedom Forum Research Group. 1992b. "From Wausau to Wichita: Covering the Campaign via Satellite." In Covering the Presidential Primaries. New York: Freedom Forum Media Studies Center, pp. 36--46.

Freedom Forum Research Group. 1992c. "The 'Virtual Newsroom."' In The Homestretch: New Politics. New Media. New Voters? New York: Freedom Forum Media Studies Center, pp. 70--82.

Jamieson, Kathleen Hall. 1992. Dirty Politics: Deception, Distraction, and Democracy. New York: Oxford University Press. 
Kolbert, Elizabeth. 1992. "Test-Marketing a President: How Focus Groups Pervade Campaign Politics." New York Times Magazine, Aug. 30.

Meyer, Philip. 1991. The New Precision Journalism. Bloomington: Indiana University Press.

Meyrowitz, Joshua. 1985. No Sense of Place: The Impact of Electronic Media on Social Behavior. New York: Oxford University Press.

Neuman, W. Russell. 1991. The Future of the Mass Audience. Cambridge: Cambridge University Press.

Postman, Neil. 1990. "Informing Ourselves to Death." Address to the German Informatics Society.

Rittner, Don. 1993. Whole Earth On-line Almanac. New York: Brady.

Salmore, Stephen A., and Barbara G. Salmore. 1985. Candidates, Parties, and Campaigns: Electoral Politics in America. Washington,

D.C.: Congressional Quarterly Press.

Schwartz, Tony. 1973. The Responsive Chord. Garden City, NY: Doubleday.

Smith, Richard J., and Mark Gibbs. 1994. Navigating the Internet. Indianapolis, IN: Sam's Publishing.

Stern, Marcus. 1992. "Campaign Techo-Marvels of 1992." Campaign Magazine 6(2); 40-41.

Times Mirror Center for the People and the Press. 1993. The Vocal Minority in American Politics. Washington, D. C.

Times Mirror Center for the People and the Press. 1994. Technology in the American Household. Washington, D.C.

Times Mirror Center for the People and the Press. 1995. Americans Going Online ... Explosive Growth, Uncertain Destinations. Washington, D.C.

\section{Biographical Note}

Michael X. Delli Carpini is Associate Professor and Chair of the Political Science Department of Barnard College, Columbia University. A specialist in American mass media and public opinion, Professor Delli Carpini's articles have appeared in numerous scholarly journals. He is the author of Stability and Change in American Politics: The Coming of Age of the Generation of the 1960s (New York: New York University Press, 1986) and a coauthor of What Americans Know about Politics and Why It Matters (New Haven: Yale University Press, 1996).

Address: Department of Political Science, Barnard College, Columbia University, New York, NY 10027

Phone: 212-854-4877

Fax: 212-854-3024

e-mail: mdelli@barnard.columbia.edu. 